the normal blood serum. This state of things continued the next day; but on the following day, six days after the commencement of the experiment, I found that at the upper end, in the vicinity of the inoculated spot, this double cyanide gauze purpled litmus, while at the lower end it still reddened turmeric. At the end of seven days the same condition persisted. After eight days, however, both the upper and lower end of the gauze purpled litmus. This peculiar septic organism, with the power of producing acid fermentation in serum, had gradually worked its way, in spite even of the cyanide of zinc and mercury; but the cyanide of zinc and mercury, you observe, had been much more efficacious than the cyanide of zinc alone. The cyanide of zinc had prevented the development of organisms that produced putrefaction, and only permitted the development of the coccus that produced acid fermentation. Cyanide of zinc and mercury had for several days prevented all development. This was proof, therefore, that the mercurial element in our compound was valuable, and that we could not dispense with it.

It may be thought an unsatisfactory thing that there shonld have been any organism able to work its way thus through a gauze charged with our antiseptic. But I may remark, in the first place, that, as above stated, we tested the material exceedingly severely; in the second place, that it was a long while before the organism penetrated the gauze even for a short distance; and, in the third place, that penetration of micro-organisms through such a dressing into wounds does not seem to occur in practice, seeing that in the year during which $I$ have used this antiseptic in my surgival work at King's College Hospital we have had no single instance in which we have had any reason to suspect septic change in the deeper parts of our dressing; we have had no instance in which deep-seated suppuration has occurred in an operation wound made through unbroken integument. If we have had any pus at all in such cases, it has been from the surfaces exposed between stitches or at situations where drainage-tubes have been inserted, where what I have termed antiseptic suppuration has occasionally shown itself, and even this in very slight degree. Such being the case, I feel not only permitted, but bound to bring this material under the notice of my professional brethren.

As to the composition of this so-called double salt, it is for the present uncertain. This much is already established : that the cyanide of mercury is in very much smaller propor tion to the cyanide of zinc than "Watts's Dictionary" would lead us to expect from a true double salt. But what the precise composition of the salt is we do not yet know. I am having it investigated by the Pharmaceutical Society, who have kindly undertaken the work.

There is another use for this material besides the charging of dressings. The powder moistened with a weak solution of corrosive sublimate may be rubbed into hairy parts, when it will convert the hairs into an antiseptic dressing. Not long ago a medical friend of mine brought his wife to me with no less than seven sebaceous cysts in the scalp, requesting me to remove them. Having washed the hair with 1 to 20 carbolic acid solution, I simply passed a comb over each tumour in the line where $I$ was about to transfix without shaving at all; and, after taking out the eysts, rubbed in some of the moistened powder into the hair in the vicinity. I then applied a dressing of cyanide gauze, and I was glad to learn that all the seven wounds had healed without disturbance.

We have now in the hospital a case of psoas abscess, shown to be of spinal origin, not only by the history of the case and the symptoms, but by the discharge of a portion of bone with the pus. That case is pursuing a course which, allow me to say, psoas abscesses will pursue in the great majority of cases, if the surgeon uses a trustworthy antiseptic, and takes the same pains with dressing to the last as at the outset; that is, he will find his trouble rewarded by the complete cure of these formerly incurable cases. I say this because I grieve to think that psoas and lumbar abscesses still seem to be regarded as hopeless affairs by many surgeons. In this man's case the temperature has never been affected in the least; he has put on flesh rapidly; the discharge, after the purulent and curdy matter that existed originally in the abscess was got rid of, has been of a serous character, and is in small and diminishing quantity. But the opening made for the discharge is in the vicinity of the pubes, and the pubic hairs used, under such circumstances, to be a constant source of anxiety to us unless frequently shaved away. Here we rub in at each dressing a little of the moistened cyanide, and convert the hairs into an antiseptic application.

I will not at present enter into the details of the preparation of this material; these will be supplied in a note on a future occasion.

The sketch which I have given you of this investigation, thou gh it has, I fear, wearied you, conveys but a small idea of the toil it has involved. There are those who still believe that the use of antiseptic substances in surgical practice is always useless, if not injurious. The germ theory of septic diseases is indeed now happily established incontrovertibly. All now admit that septic mischief in our wounds depends upon the development of microorganisms in them derived from without. But the gentlemen to whom I refer are, more or less logically, disposed to trust every thing to the antiseptic powers of thehuman tissues.

I believe I happened to be the first to direct attention to the antiseptic agency of living structures, and there is, perhaps, no one who attaches greater importance to it than $I$ do. Without it, surgery in former days would have been absolutely impossible. Still, I know too well from experience that it cannot always be trusted, and that the use of antiseptic adjutants is in the highest degree important; and I have the satisfaction of knowing that there is among you a constantly increasing number who, when they have operated on an unbroken skin, with a fair field around for the application of their dressings, if they see septic inflammation occurring in the wound with its attendant dangers, know that it is their fault or the fault of the antiseptic appliances at their disposal. To those among you who are impressed with this conviction I offer the dressing which I have described as the most satisfactory that I have hitherto met with; and I venture to hope that you will regard it as a not unwelcome addition to your resources.

\section{OSTEO-ARTHRITIS AS AN IMMEDIATE SEQUEL OF RHEUMATIC PYREXIA. ${ }^{2}$}

\section{BY J. KENT SPENDER, M.D. LOND.,}

PHYSICIAN TO THE ROYaL MINERAL Water hOSPITAL, Bath.

CLINICAL observation has established a pathological connexion of great practical interest. It has been long known that chronic rheumatism and gout may prepare the way for osteo-arthritis by lowering the textural force of the joint structures, and thus leading to morbid change of a degenerative kind. In people of the so-called tubercular diathesis, or who have near kinsfolk distinctly "consumptive," repeated rheumatic attacks may beget a condition commonly called rheumatoidal; and this, again, may gradually pass into the more complete and incurable state which enjoys the official title of Osteo-arthritis.

This clinical doctrine being fully recognised, the precise point of this paper may be formulated as follows:-A man or woman in early middle life has two or three attacks of acute rheumatism close together, affecting (perhaps) knees, elbows, or wrists; he is more or less in bed for several months; the pyrexia is rarely higher than subacute; and there are periods of quiescence during which he not only feels comparatively well, but really acts well in the sense of " muddling about," somewhat crippled it may be, but with a convalescent energy deserving praise. Nevertheless, the patient does not wholly emerge from a quasi-rheumatic condition. And it is of such sufferers that we constantly ask ourselves, especially in our Mineral Water Hospital, is this case going off rheumatoidally? is he marching in the direction of osteo-arthritis? An exceedingly practical question. Two groups of clinical phenomena appear to coalesce; the latter looks a mere postscript of the former, continuous in time and quality; in reality it is so different that the treatment calculated to moderate the one may only increase the other. The pyrexia is gone, but the pulse remains quick, or even quicker; the true rheumatic sweating has passed away, but a new type of sweating begins; and we are conscious of a fresh series of clinical phenomena, some of which are a mere continuation of the old (such as pain and enfeeblement of joints), and

1 This note will appear in our next issue.

2 Read before the Bath and Bristol Branch of the British Medical Association, on Thursday, Oct. 31st, 1889. 
others are the commencement of an entirely different order of symptoms.

Now our plea at the outset of this discussion is, that what has been described as acute rheumatoid arthritis has no clinical existence. The state of things so denominated is merely a rheumatic prodroma of rheumatoid arthritis, preparing the way and leading, on to it in subjects predisposed. There is no such predisposition in the vast majority of cases; rheumatic pyrexia comes and goes, leaving perhaps some trace of medical damage, which is usually quite remediable. ${ }^{3}$ But, after coming and going two or three times, the true rheumatism may become something else, not merely something chronic in the room of something acute, but a slow grade of an essentially different arthritic trouble, the steps of sequence to it being caught only by a practised eye. So far as joints are concerned, the transition is probably not niarked at all; what was swollen and painful remains swollen and painful; the objective lesson is not easy to read. But we pick up the threads of diagnosis by studying the concurrent facts. The pyrexia is slight, and obeys other laws; pigmentary stains and spots appear, and the neural signs of pain and muscular atrophy possess new significance. The weakness and incapability of movement increase quickly. In doubtful cases the dynamometer should be always used; little impression is made upon it by the palsy-stricken muscles of the hands. But it must be confessed that, through inattention or lack of insight, the clinical condition of the patient may undergo an entire change, without a single note being made of it by anyone.

The therapeutic issue of these considerations is of the highest moment. When the true rheumatic storm has subsided, it is notonly injudicious but very hurtful to go on prescribing salicin and the salicylate salts, and potash or soda in any guise. The iodides are equally useless, and perhaps equally injurious. Salicin is bound up with rheumatism by the closest ties; it is one of the magnificent advances of recent years; and so it follows that any arthritic affection which looks like rheumatism suggests a salicin treatment. Or if a distinct gout has preceded the osteo-arthritis, the chance is that colchicum and alkalies are continued. 'The case is now called "suppressed gout," or "latent gout," or any other dark veil of words which are algebraic signs of what we do not understand. The physician who is blind to what is going on before him had far better leave his patient alone. I cannot speak too strongly of the mischief done by this wrong system of medicine. The drugs thus wrongly given are not "phantom" drugs, idle for good or harm, but agents of positive evil. They lower the nerve tone and impoverish the blood quality; and, worst of all, they occupy that precious time during which the ingravescent osteo-arthritis should be fought with its proper weapons. When the mistake is found out, the sad legend "too late" has to be written. The unhappy patient is a life-long mourner of an irrevocable fate; and the doctor who errs from want of experience has leisure to think over an imperfect diagnosis.

To grasp the point of time when one pathological current stops and another begins is to loold the key of the position. We push aside the so-called specific remedies; we tranquillise the nervous and vaso-motor systems by quinine, belladonna, and strychnine; as soon as possible cod-liver oil and arsenic are brought to bear, to be followed at no long interval by a stable preparation of iron. There must be corresponding changes in the diet, which ought to be rich in nitrogenous and fatty material. And if we have been so unwise as to order alcohol under the poisonous garb of brandy or whisky, we shall now recommend a moderate amount of generous wine-at least four ounces daily of dry old port or of matured burgundy.

And now comes the hygienic and therapeutic touch of the Bath thermal Waters. Let them be used with every care. Iam obliged to admit that hydro-therapeutics and shampooing are sometimes overdone. The delicate atrophied creatures who submit to these processes require to have them performed in the gentle manner of reclining baths, quiet douches, and domestic massage. Most good is to be expected from our thermal Waters when there is an antecedent history of rheumatism or of gout. In other cases, when osteo-arthritis is distinctly a sign of local or general deterioration, internal medicinal treatment is of at least equal value. One more

3 The term chronic rheumatic arthritis should be strictly confined to the arthritic lesions produced by true rheumatism; the confusion of our terminology has caused confusion of ideas. caution. So-called counter-irritation (with iodine, for example) should never be done immediately over an affected joint. Such a process is essentially unscientific, for it creates an artificial excitement and hyperæmia in the very structures which we should try to keep in a quiescent mood.

The accumulation of clinical material at our thermal Spa affords a splendid school of study in osteo-arthritis. The subject is complex, with many bye-paths reaching among the thickets of physiological pathology. A complete scheme of the neurology of osteo-arthritis has yet to be unfolded. The arthritic disease, paradoxical as it sounds, may not be the central lesion at all; it may be only one member of a group of lesions, and not the most important. The writings of Sir Dyce Duckworth and Dr. Ord have contributed much to the solution of our difficulties; and rays of light are coming from many other quarters. Bath.

\section{ELEVEN CASES OF INTUBATION IN YOUNG CHILDREN.}

\section{BY IV. H. C. STAVELEY,}

HOUSE SURGEON TO THE VICTORIA HOSPITIL FOR CHILDREN, CHELSEA LATE HOUSE SURGEON TO ST. THOMAS'S 'HOSPITAL.

IN publishing the following small number of cases, I do not wish to claim that the results are more satisfactory than those of tracheotomy, but having had the opportunity of watching the cases constantly, my object is to bring into prominence the more important events which occurred during the treatment of cases of laryngeal obstruction by intubation. O'Dwyer's instruments were used in all, the size of the tube selected being in accordance with his scale. It will be seen that tracheotomy was resorted to in those cases in which it seemed that an open wound would give better hopes of relief.

CASE 1.-Frances $\mathrm{H}-$, aged thirteen months, was admitted to hospital on Dec. 12th, 1888. Previous history: Patient, who was not completely weaned, was seized with cough on the day previously to admission, arid had an attack of dyspnoea during the evening. An emetic was given with partial relief. When admitted at midday her condition was that of a feeble, rickety child, with stridulous breathing, retraction of chest wall, and cyanosis ; membrane on botl tonsils. Intubation was immediately performed, with complete relief of dyspnoea and retraction. At 4 P.M. the tube was coughed out; she breathed well for one hour, then dyspncea returned, and at 6 P.M. the tube was replaced with complete relief. Temperature $1044^{\circ}$. - 13th : At 5 A.M. much coughing and slight dyspnoea. The tube was removed, cleaned, and replaced. Breathing was then rapid but easy. Crepitations heard at right base. Temperature $105.4^{\circ}$ Taking food well.-14th : No return of dyspncea, but sank and died at 2 A.M. - Necropsy: Patches of membrane were found the whole length of the respiratory tract. Pneumonia and consolidation of lower lobes of both lungs.Remarks: A feeble child with urgent dyspnoea; the symptoms referable to laryngeal diphtheria completely relieved by intubation.

CASE 2.-Lilian B-, aged four months, was admitted to hospital on Jan. 8th. Previous history: Had been suffering from bronchitis for a month. Croupy cough began on the morning of the day of admission. Much dyspncea, stridulous cough, and recession of the ribs when admitted. No membrane seen on fauces. Coarse râles heard over both lungs. Temperature $100^{\circ}$.-Jan. 9th : Dyspnoea diminished, but increased during afternoon, with extreme recession of the chest wall. The ordinary emetics failed to induce vomiting, so an O'Dwyer's tube was inserted, but without relieving the symptoms, and was removed after a brief period. Temperature $100^{\circ}$. - 11th: Temperature rose to $105^{\circ}$, and the patient died at 6 P.M. - Necropsy: Intense congestion of the larynx and treachea, and numerous patches of membrane. Both lnngs solid, with acute pneumonia.Remarks: In this case the probabilities of the dyspnœa. being due to the condition of the lungs was fully recognised. Intubation was performed more as a means of diagnosis than with any real hope of relieving the symptoms.

CASE 3.- Maud $\mathrm{S}_{-}$, aged two years and two months, was admitted to hospital on Jan. 13th. Previous history: Sick on Jan. 11th, dyspncea began on the 12th. On admission, 